Received: 13 July 2018

Accepted: 27 June 2019

Published online: 11 July 2019

\title{
SCIENTIFIC REP

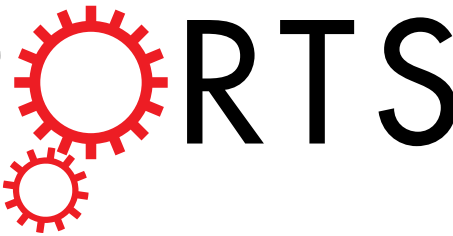

\section{OPEN Atom Probe Tomographic Imaging of PbS Quantum Dot Formation on Neodymium Clusters in Silicate}

\section{Glasses}

\begin{abstract}
Won Ji Park, Ju Eun Kim, Ho Jeong Lee, Chan Gyung Park \& Jong Heo
The first 3-D direct observation of clusters of $\mathrm{Nd}$ oxide inside silicate glasses was achieved using atom probe tomography. Three-dimensional elemental maps of major chemical elements in glasses such as $\mathrm{Si}, \mathrm{Al}, \mathrm{Zn}$ and $\mathrm{O}$ showed no evidence of regions that had concentrations higher than the average values, whereas the $\mathrm{Nd}$ aggregated into regions of high concentration. Elemental maps of $\mathrm{Nd}$ and $\mathrm{Pb}$ recorded from the glasses containing PbS ODs showed highly-concentrated areas of both elements at the same locations; this result indicates that PbS QDs formation started in association with the Nd clusters.
\end{abstract}

Rare-earth (RE)-doped glasses have been commercially used as signal amplifiers for optical communication and solid-state lasers that exploit the radiative $\mathrm{f}-\mathrm{f}$ electronic transitions of trivalent RE ions ${ }^{1-5}$. One of the fundamental difficulties associated with emission by RE ions is that when RE ions assemble into clusters, concentration quenching occurs, in which neighboring ions exchange energy non-radiatively ${ }^{6-9}$. Many spectroscopic analyses have provided indirect evidence of RE clustering ${ }^{10,11}$ but direct observation has not been reported.

Quantum dots (QDs) can provide emissions from mid-infrared to visible wavelength ${ }^{12-19}$. The optical and electronic properties of QDs depend on their size, so many attempts to realize the precise control of QDs size ${ }^{20-26}$ have been reported. In particular, in glasses that include RE ions, QDs form near clusters of RE oxides that appeared to provide nucleation sites ${ }^{27-29}$. Distribution of elements analyzed from electron energy loss spectroscopy (EELS) suggested the presence of RE clusters. However, direct evidence of the presence of the RE-oxide clusters in conventional oxide glass is lacking, and their functions in nucleation of QDs in glasses are not known.

Atom probe tomography (APT) can provide single-atom sensitivity and fine spatial resolution $(\sim 0.1 \mathrm{~nm}$ in depth) of the distribution of chemical elements in three dimensions ${ }^{30,31}$. Local electrode atom probe (LEAP) uses an additional electrode to reduce the laser damage during analyses of insulating materials. Statistical tools including iso-surface image and maximum separation method can provide additional means to detect clusters or ordered phases with sizes smaller than a few nanometers ${ }^{32,33}$. We have employed APT to visualize the presence of RE clusters in silicate glasses. We also propose how RE clusters affect nucleation and growth of QDs in glasses.

\section{Results}

Specimen preparation using a dual beam focused ion beam method. Specimens for APT analysis were prepared by a dual-beam focused ion beam (FIB; FEI, Helios Nano-Lab 650) method using the standard lift-out technique designed for insulating materials (Fig. 1) ${ }^{34-36}$. First, Pt coating was sputtered (CRESSINGTON SPUTTER COATER 208HR) on the surface of glass specimens to avoid surface damage by $\mathrm{Ga}^{+}$ions (Fig. 1a). Then a thin slice of the specimen was lifted out of bulk glass material by several successive $\mathrm{Ga}^{+}$ion-beam millings, including trench milling of $\mathrm{H}$-beam type (Fig. $1 \mathrm{~b}$ ). This specimen with $\sim 2-\mu \mathrm{m}$ width was repositioned on the tungsten tip (Fig. 1c) and further milled into a needle shape (Fig. 1d) with diameter of $\sim 40 \mathrm{~nm}$ and length of $\sim 80 \mathrm{~nm}$, that was finally loaded into the atom probe (Fig. 1e).

Three-dimensional elemental mapping and computational analyses. First, APT analysis was performed on as-prepared glass with the composition $50 \mathrm{SiO}_{2}-5 \mathrm{Al}_{2} \mathrm{O}_{3}-25 \mathrm{NaO}-10 \mathrm{BaO}-8 \mathrm{ZnO}-2 \mathrm{ZnS}-0.8 \mathrm{PbO}-$ $5 \mathrm{Nd}_{2} \mathrm{O}_{3}$ (in mol\%). In tomographic reconstructions (Fig. 2), all elements ( $\mathrm{Si}, \mathrm{O}, \mathrm{Zn}, \mathrm{Al}, \mathrm{S}$ and $\mathrm{Pb}$; Fig. 2a-f) except 


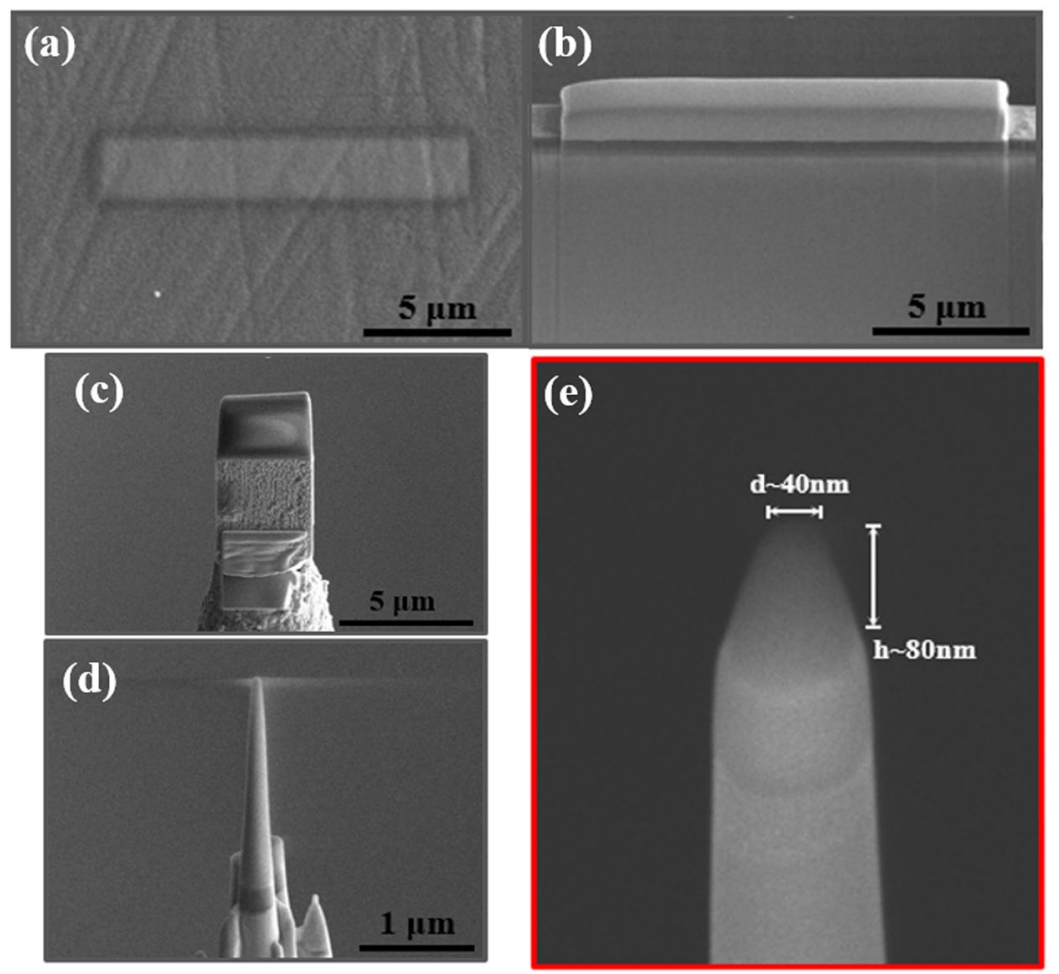

Figure 1. Procedures for preparation of tip-shaped glass specimen by using focused ion beam (FIB; FEI, Helios Nano-Lab 650) milling. (a) Pt deposition ( $15 \mu \mathrm{m}$ in length) to protect the surface of the specimen, (b) Crosssection view of a thin slab detached from the glass specimen, (c) Glass thin slab attached to tungsten tip, (d) Further milling into a needle shape, (e) Final specimen with 40-nm diameter and 80-nm length.

Analysis volume : $29 \times 29 \times 80 \mathrm{~nm}^{3}$
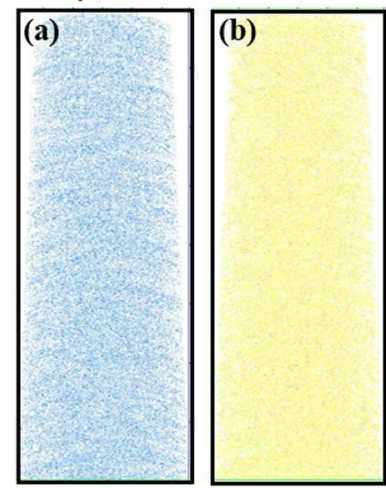
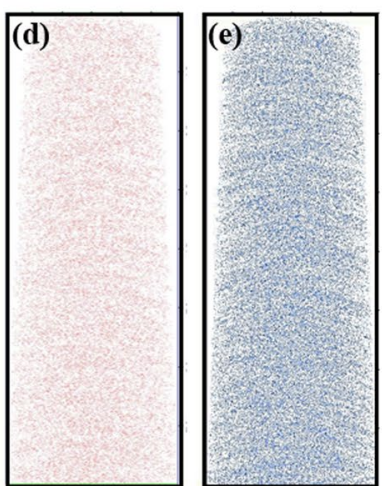
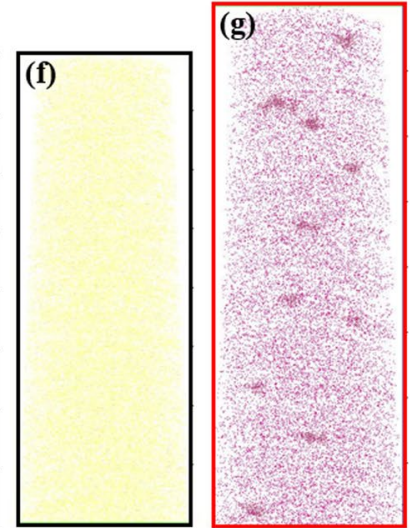

Figure 2. Three-dimensional elemental distribution maps for (a) $\mathrm{Si},(\mathbf{b}) \mathrm{O},(\mathbf{c}) \mathrm{Zn},(\mathbf{d}) \mathrm{Al},(\mathbf{e}) \mathrm{S}$, (f) $\mathrm{Pb}$ and (g) $\mathrm{Nd}$ atoms. Volumes of glass used for analyses were $\sim 29 \times 29 \times 80 \mathrm{~nm}$. Every dots corresponds to each atom and the position of an atom represents the actual location in the glass matrix.

$\mathrm{Nd}$ (Fig. $2 \mathrm{~g}$ ) were distributed homogeneously. Nd concentration ([Nd]) was high in many regions. This is the first visual three-dimensional (3D) mapping of RE clusters in a glass. Clustering of RE ions in solid matrices has been considered as a major source of the energy transfers that degrade the emission efficiencies of REs. For example, fluorescence intensity of the $\mathrm{Tb}^{3+}:{ }^{5} \mathrm{D}_{3} \rightarrow{ }^{7} \mathrm{~F}_{5}$ transition decreases as $\left[\mathrm{Tb}^{3+}\right]$ in the glass increases ${ }^{37}$. Indirect evidence such as decrease in fluorescent lifetimes and fluorescent intensities of RE ions at certain energy levels have been used to propose the presence of clustering, but this is the first 3-D direct observation of regions with RE ion concentration higher than those expected from the homogeneous distribution.

We further performed computational analysis using the iso-surface imaging method to visualize areas of high [Nd] clearly. The $1.40 \% \mathrm{Nd}$-iso surface analysis shows clear images of Nd-rich regions inside the matrix (Fig. 3a). A similar analysis for Si did not reveal any images of clustered areas, because Si was distributed homogeneously in the specimen so the analysis did not form a closed surface (Fig. 3b). The elemental concentration profile (Fig. 3c) 
Analysis volume : $29 \times 29 \times 80 \mathrm{~nm}^{3}$
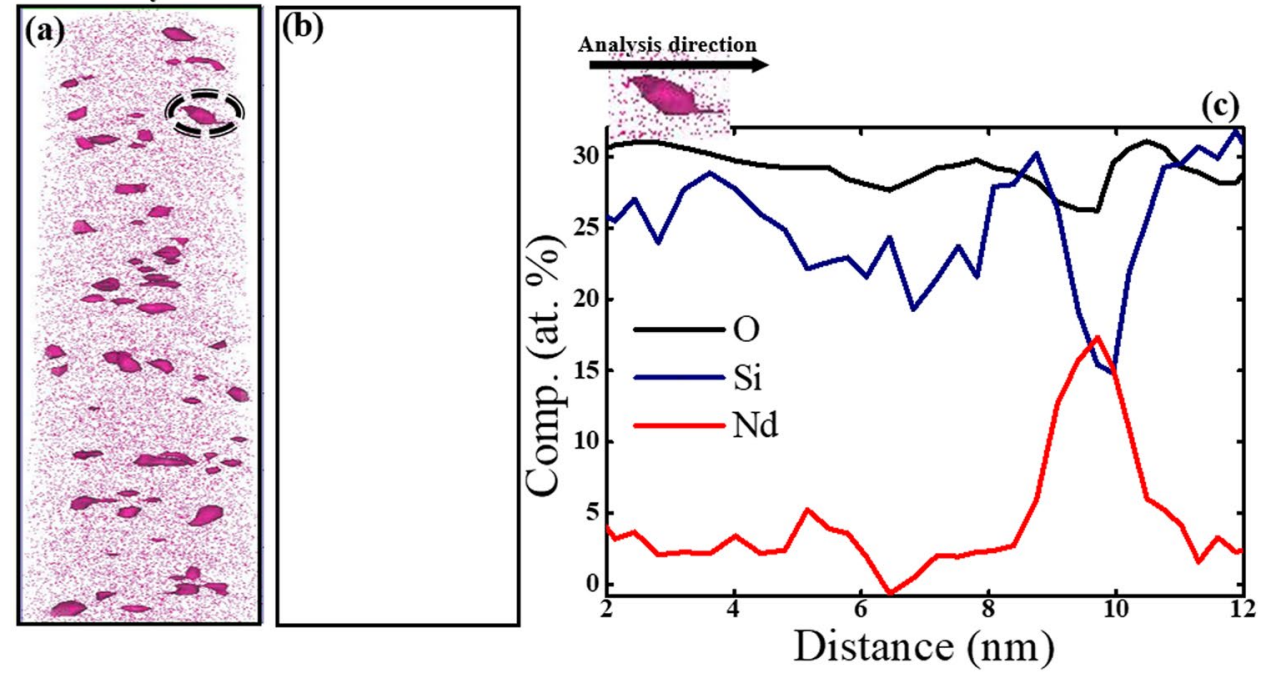

Figure 3. Isolated atom distribution image of (a) $\mathrm{Nd}$ and (b) Si obtained from the iso-surface analysis with 1.40 at.\% each atom. (c) Concentration profile of each element ( $\mathrm{Si}, \mathrm{O}, \mathrm{Nd}$ ) in a cluster of $\sim 3$-nm diameter.

Analysis volume : $40 \times 40 \times 80 \mathrm{~nm}$
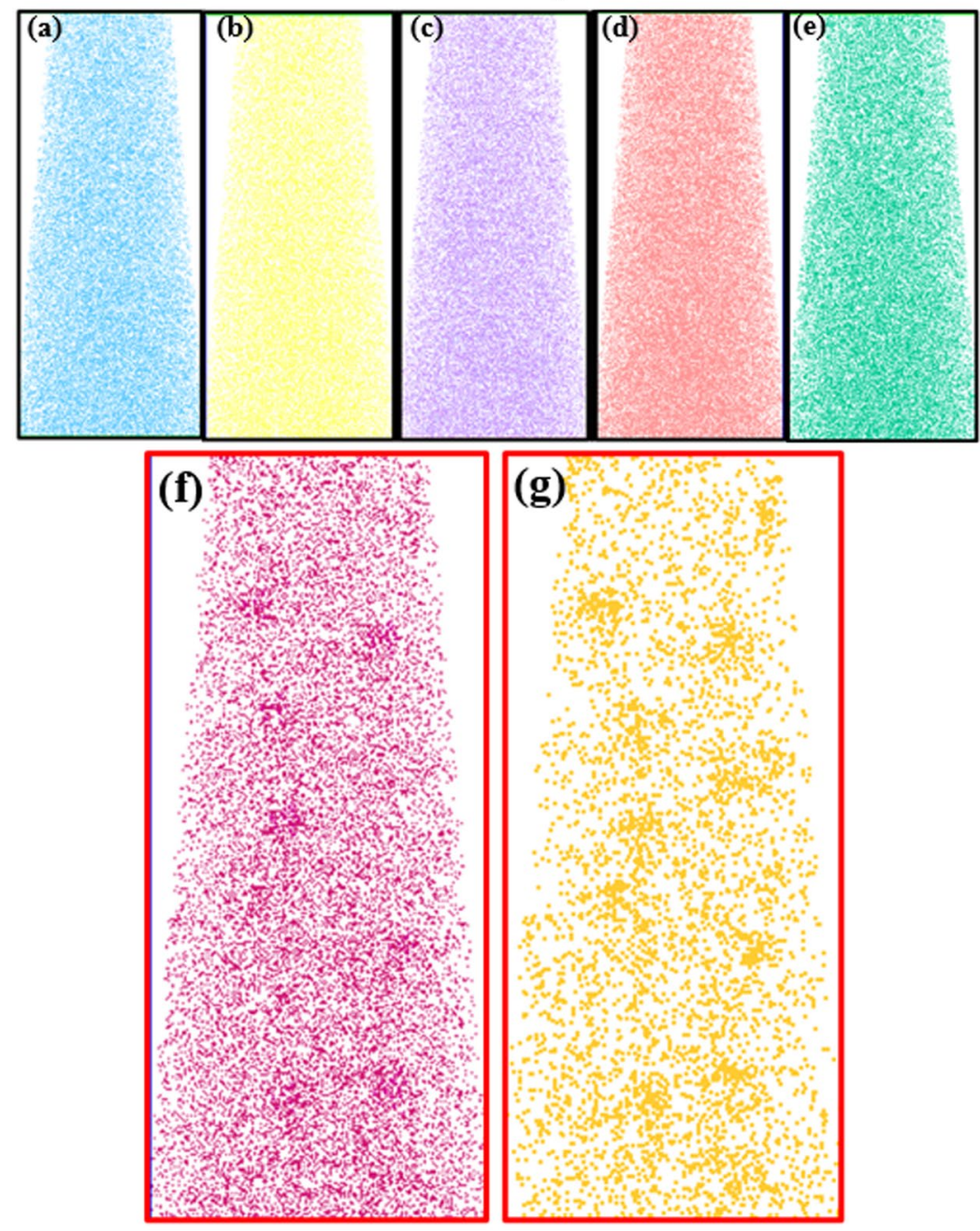

Figure 4. Three-dimensional elemental distribution maps for (a) $\mathrm{Si}$, (b) $\mathrm{O}$, (c) $\mathrm{Zn}$, (d) $\mathrm{Al}$ (e) $\mathrm{S}$, (f) $\mathrm{Nd}$ and $(\mathrm{g}) \mathrm{Pb}$ atoms in glasses after heat treatment at $500^{\circ} \mathrm{C}$ for $30 \mathrm{~h}$. Volumes of glass used for analyses were $\sim 40 \times 40 \times 80 \mathrm{~nm}$. 


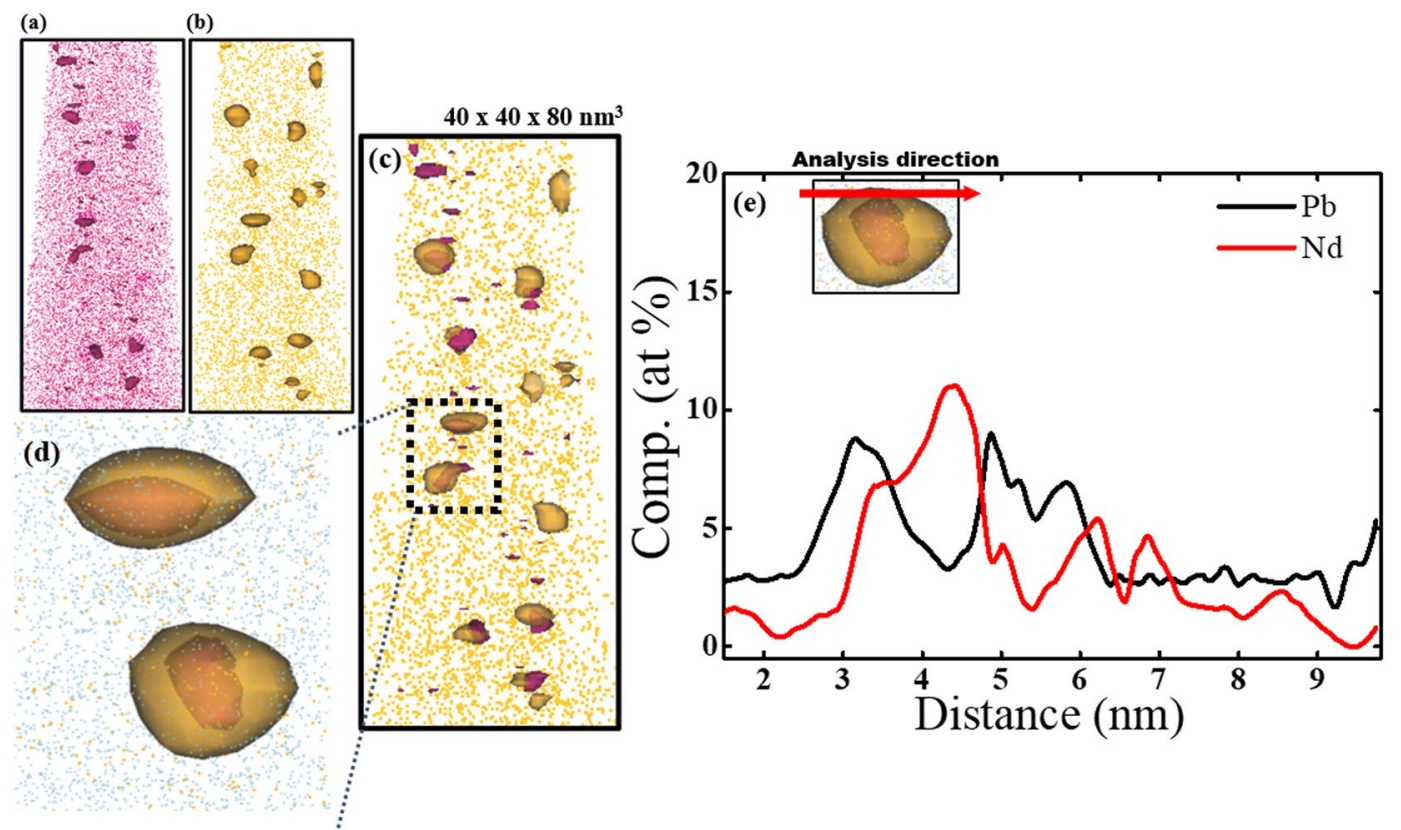

Figure 5. Isolated atom distribution image obtained from iso-surface concentration analyses of (a) $\mathrm{Nd}$ with 1.40 at.\% $\mathrm{Nd},(\mathbf{b}) \mathrm{Pb}$ with 1.40 at.\% $\mathrm{Pb}$ and (c) graphical combination of (a,b). (d) Magnified image of two PbS $\mathrm{QDs}$ in (c,e) concentration profiles of $\mathrm{Pb}$ and $\mathrm{Nd}$ in a QDs with $\sim 4$-nm diameter.

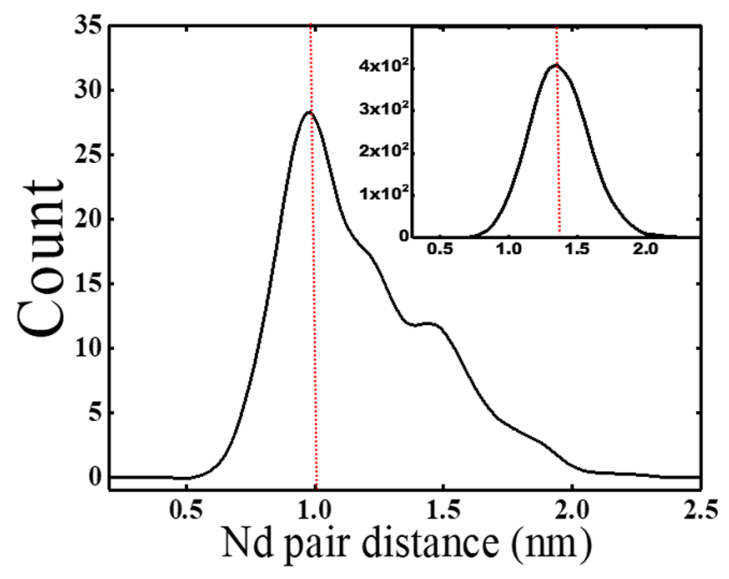

Figure 6. First nearest neighbor $(1 \mathrm{NN})$ distance $\mathrm{D}_{\max }$ distribution of $\mathrm{Nd}$ inside clusters to obtain the value of $\mathrm{D}_{\max }$ for the maximum separation method. Inset: $1 \mathrm{NN}$ distance of $\mathrm{Nd}$ in glass matrix.

recorded from one $\mathrm{Nd}$ cluster indicated that $[\mathrm{Nd}]$ atoms increased to $\sim 18$ at. $\%$ across $\sim 3 \mathrm{~nm}$ in diameter. [Si] in the cluster decreased, but $[\mathrm{O}]$ remained constant at $\sim 30$ at. $\%$.

Afterwards, glass was heat-treated at $500^{\circ} \mathrm{C}$ for $30 \mathrm{~h}$ to precipitate PbS QDs. 3D distributions (Fig. 4a) of each element were obtained from a volume of approximately $40 \times 40 \times 80 \mathrm{~nm}$ in silicate glass containing $5.0 \mathrm{~mol} . \%$ $\mathrm{Nd}_{2} \mathrm{O}_{3}$. Most of the elements (e.g., $\mathrm{Si}, \mathrm{O}, \mathrm{Zn}, \mathrm{Al}, \mathrm{S}$ atoms) that form the glass matrix were uniformly distributed (Fig. 4a-e). Some clustered areas had high [Nd] (Fig. 4f) and high [Pb] (Fig. 4g), but some $\mathrm{Nd}$ and Pb remained in the glass matrix. Regions of high [Nd] concentration (Fig. 4f) appear to overlap regions of high [Pb] (Fig. 4g).

We also conducted iso-surface compositional analyses for areas of clustered $\mathrm{Nd}$ and $\mathrm{Pb}$. Results of the analyses with $1.40 \% \mathrm{Nd}$ iso-surface concentration contour showed Nd-rich regions (Fig. 5a) similar to those in Fig. 3a. In addition, areas with high $[\mathrm{Pb}]$ (i.e., PbS QDs) were detected in glasses (Fig. 5b). In the same analysis, $\mathrm{Si}$ and $\mathrm{Al}$ atoms did not show clustering. Combination of Fig. 5a,b proved that Nd clusters almost coincide with the location of PbS QDs (Fig. 5c); this result suggests that the growth of PbS QDs is closely related to the presence of Nd clusters (Fig. 5d) and it is consistent with the results of electron energy loss spectroscopy (EELS) (Fig. S1) ${ }^{28}$. The elemental concentration profile along one QD showed that $[\mathrm{Pb}]$ increased to $\sim 10$ at.\%, and $[\mathrm{Nd}]$ increased to 12 at.\% (Fig. 5e). 


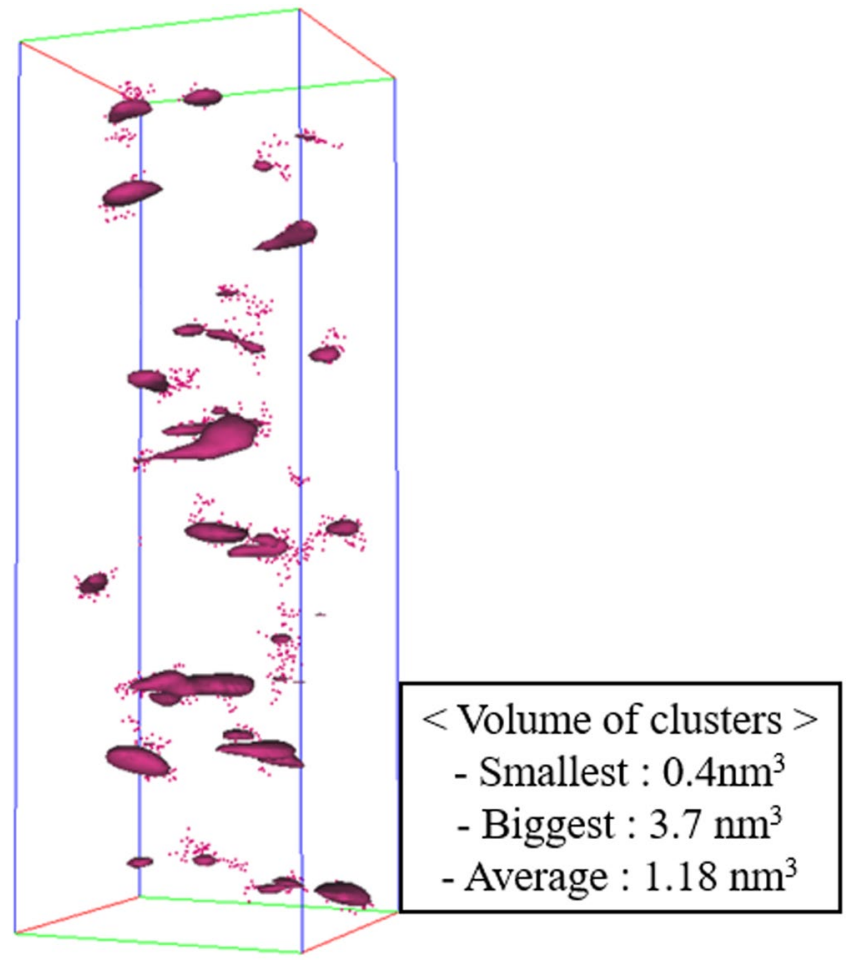

Figure 7. Analyzed Nd clusters by maximum separation algorithm with appropriate parameters. Inset table: compositional difference between clusters and glass matrix.

Nd cluster analysis using the maximum separation method. We visualized Nd clusters in 3D elemental mapping (Fig. 2) and iso-surface images (Fig. 3). We also used the maximum-separation method. The value of $\chi^{2}$ is usually determined from the distribution of Nd inside the matrix: $\chi^{2}=0$ suggests a random distribution; $\chi^{2}>0$ indicate that clusters exist ${ }^{38-40}$. The glass specimen that contained 5.0 mol.\% of $\mathrm{Nd}_{2} \mathrm{O}_{3}$ had $\chi^{2} \sim 0.93$ before heat treatment. This result is another evidence of a non-uniform and heterogeneous distribution of $\mathrm{Nd}$ in the glass matrix.

Afterwards, the Nd-Nd nearest-neighbor analysis between cluster and matrix was obtained from Fig. 6 to determine the nearest neighbor distance $D_{\max }$ between Nd atoms. Evaluation considered 14471 blocks of 100 atoms. $D_{\max }$ was $\sim 1.0 \mathrm{~nm}$ in the clusters $\sim 1.5 \mathrm{~nm}$ in the glass matrix. Other parameters considered are Order, which is the number of nearest $\mathrm{Nd}$ atoms around a specific $\mathrm{Nd}$ atom; $N_{\min }$, which is the minimum size of cluster that can be considered as a cluster; and $E$, which is the erosion distance at which an atom can be considered to have moved from the cluster to the matrix ${ }^{41}$. Numbers used for the cluster analysis were $D_{\max }=1.0, \operatorname{Order}=6$, $N_{\min }=10$ and $E=1.0 \mathrm{~nm}$; analysis detected $81 \mathrm{Nd}$ clusters in Fig. $7 \mathrm{a}$, with volumes of $0.40-3.7 \mathrm{~nm}^{3}$ (average $\left.1.18 \mathrm{~nm}^{3}\right)$. Average $[\mathrm{Nd}]$ within the clusters was 56.3 at.\%, which is $\sim 19$ times higher than the average $[\mathrm{Nd}]=3.3$ at.\% in the glass matrix.

$\mathrm{Nd}^{3+}$ ions are surrounded by an average of seven oxygens both before and after the formation of PbS QDs in glasses ${ }^{29}$. Therefore, clusters of high [Nd] (Figs 2 and 4) are most probably made of $\mathrm{NdO}_{\mathrm{x}}$ polyhedra rather than of Nd-Nd bonds. Precipitation of PbS QDs occurs in association with Nd-O clusters.

We have demonstrated the presence of Nd clusters in silicate glasses by using atom probe tomography and 3D elemental mapping. Distributions of the major chemical elements that constitute the (e.g., $\mathrm{Si}, \mathrm{Al}, \mathrm{O}$ ) showed no evidence clustering. When the glasses were heat-treated at $500^{\circ} \mathrm{C}$ for $30 \mathrm{~h}$ to precipitate the $\mathrm{PbS} \mathrm{QDs}$, areas of high $[\mathrm{Nd}]$ and $[\mathrm{Pb}]$ formed in the glasses, and closely coincide with each other; this result indicates that formation of $\mathrm{PbS}$ QDs most probably started at the Nd clusters.

\section{Method}

Glass preparation. A base glass with a nominal composition of $50 \mathrm{SiO}_{2}-5 \mathrm{Al}_{2} \mathrm{O}_{3}-25 \mathrm{NaO}-10 \mathrm{BaO}-8 \mathrm{ZnO}-$ $2 \mathrm{ZnS}-0.8 \mathrm{PbO}$ (in $\mathrm{mol} \%$ ) and a Nd-glass with an additional $5 \mathrm{~mol} \%$ of $\mathrm{Nd}_{2} \mathrm{O}_{3}$ were prepared using a conventional melt-quenching process. Starting powders were mixed and melted in an alumina crucible at $1340^{\circ} \mathrm{C}$ for $30 \mathrm{~min}$. Each melt was poured onto a brass mold that had been preheated at $380^{\circ} \mathrm{C}$, then was quenched by pressing with another brass plate. Resulting glasses were annealed at $380^{\circ} \mathrm{C}$ for $2 \mathrm{~h}$ to eliminate residual thermal stress. Specimens were polished to $\sim 150-\mu \mathrm{m}$ thickness, then used as a source for fabrication by FIB of specimens for APT.

Atom Probe Tomography (APT). APT analysis (CAMECA, LEAP4000X HR) was performed using a pulsed UV laser $(\lambda=355 \mathrm{~nm})$ and each atom was detached from the surface by irradiating the laser beam with 
$100-\mathrm{pJ}$ pulse energy at a repetition rate of $200 \mathrm{kHz}$. An additional local electrode with a range of $2-15 \mathrm{kV}$ was used to avoid the specimen damage by the laser beam. IVAS software (3.6.10a version) by CAMECA Instruments was used to reconstruct and visualize APT results. Cluster formation was identified from the iso-surface concentration. The maximum-separation algorithm was used to distinguish the clusters from the matrix, and the corresponding differences between the matrix and cluster compositions were calculated.

\section{References}

1. Kotani, A. et al. Theory of core-level spectroscopy of rare-earth oxids. J. Electron. Spectrosc. Relat. Phenom. 60, 257-99 (1992).

2. Mozian, V. et al. $\mathrm{Er}^{3+}$-doped GeGaSbS glasses for mid-IR fibre laser application: Synthesis and rare earth spectroscopy. Opt. Mater. 31, 39-46 (2008)

3. Chu, Z. et al. Water-vapor absorption line measurements in the 940-nm band by using a Raman-shifted dye laser. Appl. Opt. 32, 992-8 (1993).

4. Campbell, J. et al. Nd-doped phosphate glasses for high-energy/high-peak power lasers. J. Non-Cryst. Solids 263, 318-41 (2000).

5. Yamanaka, C. et al. Nd-doped phosphate glass laser systems for laser fusion research. IEEE J. Quantum Electron. 17, 1639-49 (1981).

6. Arai, K. et al. Aliminium or phosphorus co-doping effects on the fluorescence and structural properties of neodymium-doped silica glass. J. Appl. Phys. 59, 3430-6 (1986).

7. Ainslie, B. J. et al. Optical and structural investigation of $\mathrm{Nd}^{3+}$ in silica-based fibers. J. Mater. Sci. Lett. 6, 1361-3 (1987).

8. Morkel, P. R. et al. Spectral variation of excited state absorption in neodymium doped fiber lasers. Opt. Commun. 67, 349-52 (1988).

9. Aitken, B. G. et al. Clustering of rare earths in GeAs sulfide glass. C. R. Chimie 5, 865-72 (2002).

10. Monreil, A. et al. Clustering of rare earth in glasses, aluminum effect: experiments and modeling. J. Non-Cryst. Solids 348, 44-50 (2004).

11. Mizoguki, T. et al. Atomic-Scale Identification of Individual Lanthanide Dopants in Optical Glass Fiber. ACS nano 7, 5058-63 (2013).

12. Bakueva, L. et al. Size-tunable Infrared (1000-1600 nm) Electroluminescence from PbS Quantum-dot Nanocrystals in a Semiconducting Polymer. Appl. Phys. Lett. 82, 2895-7 (2003).

13. Steckel, J. S. et al. $1.3 \mu \mathrm{m}$ to $1.55 \mu \mathrm{m}$ Tunable Electroluminescence from PbSe Quantum Dots Embedded Within Organic Device. Adv. Mater. 15, 1862-6 (2003)

14. Kamat, P. V. Quantum Dot Solar Cells. Semiconductor Nanocrystals as Light Harvesters. J. Phys. Chem. C 112, 18737-53 (2008).

15. Kamat, P. V. Meeting the Clean Energy Demand: Nanostructure Architectures for Solar Energy Conversion. J. Phys. Chem. C 111, 2834-60 (2007).

16. Colvin, V. L. et al. Light-emitting diodes made from cadmium selenide nanocrystals and a semiconducting polymer. Nature 370, 354-7 (1994).

17. Sullivan, S. C. et al. Tuning the performance of hybrid organic/inorganic quantum dot light-emitting devices Org. Eletron. 4, 123-30 (2003).

18. Tittel, J. et al. Fluorescence Spectroscopy on Single CdS Nanocrystals. J. Phys. Chem. B 101, 3013-6 (1997).

19. Wang, Y. et al. Nanometer-Sized Semiconductor Clusters: Materials Synthesis, Quantum Size Effects, and Photophysical Properties. J. Phys. Chem. 95, 525-32 (1991).

20. Liu, C. et al. Laser-induced blue-shift of the photoluminescence from PbS quantum dots in glasses. Chem. Phys. Lett. 452, 281-4 (2008).

21. Moreels, I. et al. Size-Dependent Optical Properties of Colloidal PbS Quantum Dots. ACS Nano 3, 3023-30 (2009).

22. Liu, C. et al. Photoluminescence of PbS quantum dots embedded in glasses. J. Non-Cryst. Solids 354, 618-23 (2008).

23. Heo, J. et al. PbS quantum-dots in glass matrix for universal fiber-optic amplifier. J. Mater. Sci.: Mater. Electron. 18, S135-9 (2007).

24. Shim, S. M. et al. Lead Sulfide Quantum Dots Formation in Glasses Controlled by Erbium Ions. J. Am. Ceram. Soc. 93, 3092-4 (2010).

25. Xu, K. et al. Influence of silver nanoclusters on formation of PbS quantum dots in glasses. J. Non-Cryst. Solids 357, 2428-30 (2011).

26. de Lamaestre, R. E. et al. Synthesis of Lead Chalcogenide Nanocrystals by Sequential Ion Implantation in Silica. J. Phys. Chem. B 109, 19148-55 (2005).

27. Kim, M. A. et al. Lead Sulfide Quantum Dots in Glasses Containing Rare Earth Ions. J. Non-Cryst. Solids. 383, 173-5 (2014).

28. Park, W. J. et al. Direct Imaging of the Distribution of $\mathrm{Nd}^{3+}$ ions in Glasses Containing PbS Quantum Dots. J. Am. Ceram. Soc. 98, 2074-7 (2015).

29. Park, W. J. et al. Role of $\mathrm{Nd}^{3+}$ ions on the nucleation and growth of PbS quantum dots (QDs) in silicate glasses. J. Am. Ceram. Soc. 100, 2879-84 (2017).

30. Muller, E. W. et al. Atom-Probe Field Ion Microscope. Rev. Sci. Instrum. 39, 83-6 (1968).

31. Cerezo, A. et al. Atom probe tomography today. Mater. Today 10, 36-42 (2004).

32. Tsong, T. Atom-Probe Field-Ion Microscopy. Cambridge Univ. Press (1990).

33. Miller, M. K. et al. Atom probe tomography of nanoscale particles in ODS Ferritic alloys. Mater. Sci. Eng. 353, 140-5 (2003).

34. Kelly, T. F. et al. Invited review article: Atom probe tomography. Rev. Sci. Instrum. 78, 031101-20 (2007).

35. Seidman, D. N. Three-dimensional atom-probe tomography: Advances and applications. Annu. Rev. Mat. Res. 37, 127-58 (2007).

36. Miller, M. K. Materials science - Imaging elusive solute atoms. Science 286, 2285-6 (1996).

37. Tonooka, K. et al. A non-linear analysis of energy transfer in highly $\mathrm{Tb}^{3+}$-doped glasses. J. Lumin. 50, 139-51 (1991).

38. Blavette, D. et al. An Atom-Probe for 3-Dimensional Tomography. Nature 363, 432-5 (1993).

39. Marquis, E. A. et al. Applications of atom-probe tomography to the characterization of solute behaviors. Mat. Sci. Eng. R 69, 37-62 (2010).

40. Williams, C. A. et al. Defining clusters in APT reconstructions of ODS steels. Ultramicroscopy 132, 271-8 (2013).

41. Thompson, K. et al. In-situ site-specific specimen preparation for atom probe tomography. Ultramicroscopy 107, 131-9 (2007).

\section{Acknowledgements}

This research was supported by a Basic Science Research Program (NRF-2017M2B2B1072405) through the National Research Foundation (NRF) funded by the Ministry of Science and ICT, Korea.

\section{Author Contributions}

J. Heo conceived and coordinated the research project. W.J. Park designed the glass compositions and prepared the specimens and H.J. Lee conducted TEM and the compositional analysis. J.E. Kim performed APT measurement and C.G. Park guided J.E. Kim for the cluster analyses. All authors participated in discussion and manuscript preparation. 


\section{Additional Information}

Supplementary information accompanies this paper at https://doi.org/10.1038/s41598-019-46574-1.

Competing Interests: The authors declare no competing interests.

Publisher's note: Springer Nature remains neutral with regard to jurisdictional claims in published maps and institutional affiliations.

(c) (1) Open Access This article is licensed under a Creative Commons Attribution 4.0 International License, which permits use, sharing, adaptation, distribution and reproduction in any medium or format, as long as you give appropriate credit to the original author(s) and the source, provide a link to the Creative Commons license, and indicate if changes were made. The images or other third party material in this article are included in the article's Creative Commons license, unless indicated otherwise in a credit line to the material. If material is not included in the article's Creative Commons license and your intended use is not permitted by statutory regulation or exceeds the permitted use, you will need to obtain permission directly from the copyright holder. To view a copy of this license, visit http://creativecommons.org/licenses/by/4.0/.

(C) The Author(s) 2019 